\title{
How Does Energy Resource Depletion Affect Prosperity? Mathematics of a Minimum Energy Return on Investment (EROI)
}

\author{
Adam R. Brandt ${ }^{1}$
}

Received: 26 October 2016 / Accepted: 28 January 2017 / Published online: 16 March 2017

(C) Springer International Publishing Switzerland 2017

\begin{abstract}
It has been proposed that energy resource depletion and declining energy return on investment (EROI) can disrupt modern, prosperous lifestyles. This is because such lifestyles are dependent on abundant, lowcost energy supplies, to date supplied by fossil energy. We illustrate a mathematical structure by which to analyze the impacts of energy depletion as it affects all sectors of the economy. This framework is based on the reduced availability of discretionary outputs as inter-industry operations become less efficient. We illustrate this mathematical framework, and explore a simple template economy with four sectors. The inputs for each sector are defined at an order-of-magnitude level using data for the US, and the matrix is modified to explore the impacts of resource depletion and uncertainty. We show that the "net energy cliff" concept used in prior studies emerges from the structure of this template economy and appears at similar levels of energy productivity hypothesized in prior work. At levels of net energy return $\leq 5 \mathrm{~J} / \mathrm{J}$, the fraction of productive outputs free to use in discretionary purposes declines rapidly, resulting in the emergence of an effective "minimum EROI" below which prosperity is burdened by excessive direct and indirect requirements of the energy sector. We explore how uncertainty in the matrix specification impacts the level at which the minimum EROI becomes binding. We also show how changes in other sectors (e.g., efficiency of materials production) can affect the rate at which energy depletion affects prosperity.
\end{abstract}

Adam R. Brandt

abrandt@stanford.edu

1 Department of Energy Resources Engineering, Stanford University, Stanford, USA
Keywords Energy return on investment (EROI) . Prosperity · Depletion

\section{Introduction}

The availability of abundant, affordable energy is a key feature of modern, prosperous societies. A society and its component parts (e.g., people, other organisms, machines) are physical systems dependent on inflows of energy resources with high thermodynamic quality. Such resources are "consumed" to power various functions in society. Of course, energy is never consumed per se, and instead the energy content of an energy resource is destroyed and its thermodynamic work potential is depleted as the energy is converted to waste heat. Modern systems largely consume stored chemical energy in the form of fossil fuels, which raises profound sustainability concerns, both regarding supply of enough fossil fuels and the environmental impacts of large-scale fossil fuel use.

In the next century, humanity will re-engineer its basic societal "metabolism". This has only happened a few times in the past. Early hunting and gathering societies made a living chasing fickle herds of animals. Large effort was required, but payoffs upon success were large. Agricultural societies later managed large landscapes of productive crops, an innovation that allowed for more stable and consistent surplus. Such surplus was invested in humanand animal-powered machinery and allowed for intensive gatherings of people in early cities. Such yields eventually resulted in large population increases and social complexity arose repeatedly when the abundance of agricultural systems allowed for management and knowledge classes to emerge (Tainter 1988). The shift to consuming fossil energy augmented chemical energy as food for humans 
and animals, and effectively decoupled human energy use from natural flows (Smil 1994; Fouquet 2008). This discovery of fossil energy came none-too-soon, as global forests were facing an ever-increasing assault (Perlin 1989) due to increasing industrial demands (e.g., iron production).

Due to the overwhelming dependence of our highenergy society on fossil fuels, concerns have been raised for at least a century about the sustainability of fossil fuelbased energy systems (Brandt 2011; Deffeyes et al. 2005). One specific concern relates to the energetic productivity of energy resources in the face of depletion (Hall et al. 2009). This concern was raised repeatedly starting in the 1980 s by Hall and Cleveland (1981) and Hall et al. (1986, 2003).

The modern form of this concern is often framed as a challenge of energy resource productivity. Gathering energy resources from the earth generally consumes large amounts of labor, energy, and capital. One can conceptualize an energy return ratio, or ERR, as the amount of energy supplied by an energy resource divided by the energy consumed in gathering that resource. The most well-known of these ratios is the energy return on investment, or EROI, though many similar metrics have been invented since the 1970s (Brandt et al. 2012). A number of methodological challenges arise when computing ERRs, including system boundary consistency, comparative valuation of energy resources of different quality, and developing consistent analysis methods for quite different resources and energy carriers (Brandt and Dale 2011; Brandt et al. 2013; Murphy et al. 2011; Cleveland et al. 2000).

ERRs are conceptually related to measures of energy productivity. A very productive resource will yield a large amount energy to society for each amount of input consumed. For example, productive energy resources will have high yields per unit of labor, energy, or built capital expended. In contrast, a meagre resource will require large amounts of energy (or other inputs) and yield only a small amount of energy surplus. Since all non-energy sector activities must, by definition, consume the surplus output of the energy sector, this energetic surplus underlies all other economic activities.

A recent question raised by Hall and others relates specifically to the interaction of EROI and prosperity (Hall et al. 2009; Lambert et al. 2014). They argue that there is minimum EROI value which can support modern, prosperous societies (Hall et al. 2009; Lambert et al. 2014). At lowered energy productivity levels-or lower EROI levels-energy becomes expensive and costly to obtain, and consumption of energy to support non-essential 'highlevel" functions of society becomes infeasible. Hall et al. argue for basic "rule of thumb" quantitative values for the minimum EROI for a prosperous society, arguing that below a ratio of $3: 1$, maintenance of a modern society is impossible (Hall et al. 2009). Hall et al. do not provide a general mathematical or theoretical framework to support calculation of such cutoff values, which is a gap that this paper seeks to fill.

Following on the work of Hall et al. on minimum EROI, a number of studies have explored the various features of declining EROI on society. Murphy and Hall (2010) describe a "net energy cliff" in which declining EROI results in rapid increases in the fraction of energy dedicated to simply supporting the energy system. King and Hall (2011) examined the relationship between energy prices and energy return on investment, suggesting that energy prices reflect the cost of energy required to harvest that energy resource and, therefore, declining EROI will result in higher energy prices and less prosperity. In a related paper, Heun and de Wit explore the relationship between oil prices and EROI using a statistical model with a half century of oil price and EROI inputs (Heun and de Wit 2012). They find a relationship between EROI and prices, and note that energy prices may break down in acting as an "indicator" of scarcity, particularly as the EROI becomes small.

Lastly, connections between economic and net energy metrics have been explored in detail elsewhere (King et al. 2015). Lambert et al. (2014) examine the relationship between EROI and various measures of prosperity, quality of life, and social equality (e.g., human development index, female literacy, underweight children). They also create a composite energy indicator which includes the energy return on investment, absolute energy availability, and economic inequality. They argue that this new indicator is more useful for predicting various social outcomes than simple measures of per-capita energy consumption.

These studies raise a number of interesting questions. From a theoretical or mathematical perspective, some fundamental questions include:

- What is the causal mechanism by which declining energy resource productivity (i.e., declining EROI) affects overall societal prosperity?

- Do impacts to prosperity arise from the structure of the energy sector, or do they arise due to the relationship of energy sector outputs to other economic activity?

- Is the so-called "net energy cliff" an unavoidable aspect of declining energy productivity?

In this paper, we develop a multi-sector matrix-based method for addressing the above questions. It allows us to quantify, for the first time, the impacts of declining ERRs on societal prosperity. Our mathematical method is based partially on prior work on matrix-based approaches to computing ERRs (Brandt and Dale 2011; Brandt et al. 2012). In that formulation, a matrix was defined using a method based on matrix-based approaches to life cycle assessment 
(LCA). In LCA, interactions across the economy are presented as a flow matrix where columns are processes and rows are products. In that framework, we define a matrix $\mathbf{A}$ of flows between processes and note that to produce a vector of final demand $\mathbf{f}$ we need to scale the flow matrix $\mathbf{A}$ by a scaling vector $\mathbf{s}$ :

As $=\mathbf{f}$.

Therefore, we can solve for the scaling vector $\mathbf{s}$ as:

$\mathbf{s}=\mathbf{A}^{-1} \mathbf{f}$.

This scaling vector $\mathbf{s}$ can then be used to scale flows to and from the environment:

$\mathbf{g}=\mathbf{B s}$

where $\mathbf{B}$ is the matrix of flows between the natural environment and the economy associated with inter-process flow matrix A.

In that prior work, the elements of $\mathbf{g}$ and $\mathbf{f}$ were used to define various ERRs, such as:

$\mathrm{NER}=\frac{\sum_{i \in E} \mathbf{f}_{i}}{\mathbf{t} \cdot \mathbf{g}}$,

where $E$ is the set of energy production processes and $\mathbf{t}$ is an indicator vector denoting which flows represent consumed energy dissipated as waste heat into the environment (see Brandt et al. 2012 for more details). In this formulation, the matrix framework applied is that of Heijungs and Suh (2002).

In this paper we generate a similar, though distinct, model. This model is more closely based on inter-sector flows modeling using formulations from Input-Output (IO) economics. We first outline a simple two-sector explanation of a measure of prosperity. We use the intuition gained here to define a measure of prosperity than can be readily studied and examined under varying levels of energy sector productivity. We then explore a four-sector, order-of-magnitude template economy. We define this template matrix using realistic, if approximate, values from the modern United States, and explore its behavior during reductions in energy sector productivity. We then explore the impacts of matrix uncertainty on the results, and explore how othersector productivity changes (e.g., material sector) interact with and mediate the role that energy abundance plays in general prosperity.

\section{Methods}

We develop a method-based on linear algebra of interacting processes - to better understand the impact of energy resource productivity on societal prosperity. The first step toward a mathematical framework is to make more explicit what is meant by "prosperity". An explicit definition is important because choosing a mathematical definition of prosperity will point to a specific means of estimation or modeling.

In this paper, we tentatively-and usefully, as will be shown-define prosperity as follows: a society is more prosperous if a larger fraction of the output from the economic system is free to put to use for discretionary uses. That is, a society is more wealthy when more of the produce of the economic system is not used simply to operate the basic economic system (i.e., inter-industry trade) but can be diverted to use by consumers as they see fit (i.e., final demand).

Many other reasonable measures of prosperity might exist. One might, for example, measure absolute material or energy output per capita (e.g., total $\mathrm{kg}$ or total MJ). We would counter, however, that what contributes to prosperity is not simply total economic output, but the fraction of that output that can be directed toward discretionary uses. As an illustration, imagine two societies where per-capita gross outputs from the chemicals sector are identical. If the first of these societies has extremely poor quality farmland and insect infestation, then the per-capita chemical industry output might be disproportionately dedicated to the agricultural sector to simply allow production of basic foodstuffs. Meanwhile, if the second society has a more bountiful set of farmland resources, the chemical sector outputs could be increasingly directed toward any manner of discretionary uses.

A prosperous society, therefore, is able to invest more of its produce (be it steel, glass, or high-skilled services) into discretionary activities. These might include advanced education, science, entertainment, temperature controlled living and working spaces, or discretionary travel. Obviously, such activities are possible only when productive sectors are efficient enough that some abundance is left over after the basic requirements of the subsistence economic processes are met.

How does this definition relate to energy supply? A simple example will illustrate the impacts of declining energy resource quality on prosperity. Figure 1 shows a "toy" twosector economy with "energy" and "materials" sectors, with
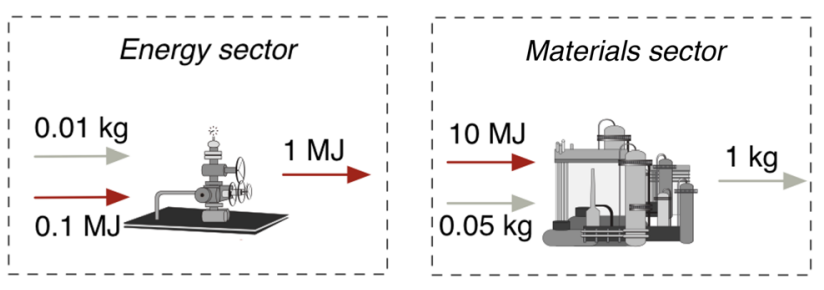

Fig. 1 Illustrative two-sector model containing only an energy sector and a steel sector. These flows are for time period $t_{1}$ before resource depletion occurs 
the magnitude of flows specified for an initial time period, called $t_{1}$. The output functional units for each sector are $1 \mathrm{MJ}$ of energy and $1 \mathrm{~kg}$ of materials, respectively. The energy sector self-consumes $10 \%$ of its output in processing and refining the energy source, and consumes $0.01 \mathrm{~kg}$ of material (e.g., steel) for every MJ of output. Similarly, the materials sector consumes $10 \mathrm{MJ}$ of energy for every $\mathrm{kg}$ of material produced and requires $5 \%$ of its own output for operation.

Using the framework of Leontief et al., with notation from Miller and Blair (2009) we can write these flows as a transactions matrix $\mathbf{A}$ for $t_{1}$ as:

$$
\mathbf{A}_{1}=\begin{array}{r}
\text { Energy } \\
\text { Enterials }\left|\begin{array}{cc}
0.1 & 10 \\
0.01 & 0.05
\end{array}\right| .
\end{array}
$$

We note that $\mathbf{A}$ is a "mixed units" matrix in which the first column represents inputs to the energy sector, and the second inputs to the materials sector. The rows, in contrast, represent so-called "inter-industry" outputs from each sector to each other sector (including itself). We can then construct the Leontief inverse:

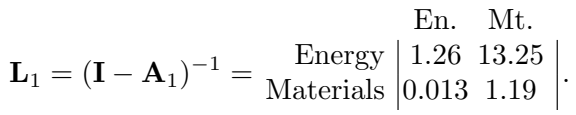

Now, let us imagine that we desire $1 \mathrm{MJ}$ of total energy output for final demand outside of this two sector economy (i.e., any activity whose outputs is not consumed by another productive sector). To support this final demand $\mathbf{f}$ of energy of 1 unit (i.e., $\mathbf{f}^{\mathrm{T}}=[1,0]$ ), not to be used by the steel sector, the total (gross) production required is:

$\mathbf{s}_{1}=\left(\mathbf{I}-\mathbf{A}_{1}\right)^{-1} \mathbf{f}=\mathbf{L}_{1} \mathbf{f}=$\begin{tabular}{r|c} 
Energy & 1.26 \\
Materials & 0.013
\end{tabular} \mid.

Thus, the system must produce $1.26 \mathrm{MJ}$ of total energy to allow final demand use of $1 \mathrm{MJ}$ of energy. Similarly, for $1 \mathrm{~kg}$ of discretionary steel use the same procedure shows us that gross steel output must be $1.19 \mathrm{~kg}$.

Let us suppose that in time period $t_{2}$ energy resource depletion has lowered the average quality of oilfields being tapped in this simple economy. The oilfield must now be pumped harder and more wells must be drilled. For the sake of concreteness, let self-consumption of energy rise to $15 \%$ of gross output, and steel requirements double to $0.02 \mathrm{~kg}$ per MJ. The matrix in $t_{2}$ then becomes:

$$
\begin{aligned}
& \text { En. Mt. } \\
& \mathbf{A}_{2}=\begin{array}{r|ll}
\text { Energy } & 0.15 & 10 \\
\text { Materials } & 0.02 & 0.05
\end{array}
\end{aligned}
$$

and our scale vector of total demands is:

$\mathbf{s}_{2}=\left(\mathbf{I}-\mathbf{A}_{2}\right)^{-1} \mathbf{f}=\mathbf{L}_{2} \mathbf{f}=$\begin{tabular}{r|c} 
Energy & 1.56 \\
Materials & 0.033
\end{tabular} \mid.

Note that both terms of $\mathbf{s}$ have changed. There are two ways to interpret the change that occurred. The first is that to support the use of one unit of energy for discretionary purposes, more total energy output is required. That is, gross energy output grows to $1.56 \mathrm{MJ}$. In this case there are two causes for this change: direct within-sector consumption increases due to increased pumping energy (i.e., $A_{11}$ changes from 0.10 to 0.15 ), and increased indirect consumption due to increased steel requirements.

Another interpretation of the above changed $\mathbf{s}$ is that the fraction of energy sector gross production that is free to allocate to discretionary use drops. That is, for an energy sector of a given capacity for total gross output, less net output is available after inter-industry demands are met. We might define a ratio of the discretionary (final) energy use over the total energy use, $\mathbf{f}_{1} / \mathbf{s}_{1}$, which declines from 0.79 $\mathrm{MJ} / \mathrm{MJ}$ (or $1 / 1.26$ ) in $t_{1}$ to $0.64 \mathrm{MJ} / \mathrm{MJ}$ in $t_{2}$.

This result points to a more general framework for estimating the impacts of resource depletion on prosperity. We will develop this framework below.

First, we must re-cast the definitions of matrix-based ERRs shown in previous work. We can say that:

$\mathrm{NER}=\frac{\mathbf{f}_{e}}{\mathbf{s}_{e}-\mathbf{f}_{e}}$

where $\mathbf{f}_{e}$ is the energy sector element of the demand vector (e subscript indicates the placeholder for energy sector vector element or energy sector column of array $\mathbf{A}$ ). Or, otherwise expressed, final demand of energy divided by the energy consumed to supply that final demand. In contrast, the GER counts as output from the sector all consumed energy:

$\mathrm{GER}=\frac{\mathbf{s}_{e}}{\mathbf{s}_{e}-\mathbf{f}_{e}}$

where subscript notation follows from above.

How might we measure discretionary use? Of course, the distinction between discretionary and non-discretionary (subsistence) consumption is always fuzzy. However, a useful corollary in IO models is given by intermediate (inter-industry) demand and final demand. If we make the assumption that our economic matrix represents primarily the "basic" or "subsistence" side of the economy, focused on supplying primary goods, then all other activity would be modeled as final demand. Final demand is what we want as consumers, and total demand (final plus intermediate demand) is what sectors must produce in total to supply our final demand. In the language of Miller and Blair, such a model has "exogenized" consumption that is discretionary. Any calls for discretionary goods would then be included in the final demand vector (Miller and Blair 2009). Alternatively, in IO terms we have made the system more "open" and less "closed" (Miller and Blair 2009).

A mathematical definition of prosperity can be defined using the fraction of production of a given resource that is 
"free" to be used in discretionary activities. Stated alternatively: for each unit of final demand that is desired for discretionary uses, how much additional requirement is there for production of the product simply to maintain the production system? For systems with high prosperity, a large fraction of a given resource (human labor, energy, materials) is free to allocate as we please. In systems that are closer to subsistence, a large fraction of the output of any product must be "plowed back" into powering industrial processes. A striking fact of a subsistence economy in comparison to the modern economy is that in a modern economy comparatively few of the hours we work, or very little of the material output we consume, are directly related to basic subsistence.

Thus, to generalize on the equation above, if we demand 1 unit of output as discretionary demand, how much total production must occur (intermediate + final demand)? This ratio represents the amount of each product that is effectively free to use in discretionary activities for a given amount of gross output. Because we define implicitly the system as open to all discretionary consumption, the desired discretionary output from the system is simply given by $\mathbf{f}$ and the total requirements for each product are given by $\mathbf{s}$ and, therefore, a measure of the efficiency of a sector $i$ can be determined to be a ratio $\mathbf{r}$ :

$\forall i \in 1 \ldots n: \mathbf{r}_{i}=\frac{\mathbf{f}_{i}}{\mathbf{s}_{i}}$

where $n$ is the total number of productive sectors in the economy. We can imagine a threshold value defined as $\theta_{i}$ , which is a value of $\mathbf{r}_{i}$ below which we cannot call a system prosperous. For example, we might require a threshold value $\theta_{i}$ of 0.66 for all products, suggesting that a society cannot be considered prosperous if less than $66 \%$ of its productivity is free to consume in discretionary uses. As production of a given output becomes less efficient, this ratio $\mathbf{r}$ of free material/energy/food/labor drops. We move toward a more subsistence economy, where more and more of our output is required to sustain the industrial system.

Note that inverting the production matrix $\mathbf{A}$ results in the infinite series of interactions between all sectors. This means that energy productivity can be dragged down by drops in the efficiency of the labor sector, or changes in the efficiency of the materials production sector will affect all other sectors as well. It is not just rising or dropping energy extraction performance that affects productivity, but changes throughout the system.

To explore the dynamics of an economic system as energy resource productivity declines, we generate a template economy, and change the productivity of the energy sector to see how this effects the general level of prosperity. For ease of explanation, we work with a highly theoretical four-sector economy. This economy includes an energy sector, materials sector, food sector, and labor sector. We will show that this simple economy behaves in ways that are congruent with current theories about the impacts of energy resource productivity. This four-sector model has similarities with the five-sector capital, labor, energy, materials, and services (KLEMS) models used in some economic sub-disciples (Gullickson and Harper 1987).

\section{A Template Order-of-Magnitude Economic System}

To generate a working example below, we will work with a very simple four-sector model. Our aggregate sectors produce three generic physical products: energy, materials, and food with dimensionality of $(\mathrm{MJ}),(\mathrm{kg})$, and $(\mathrm{kg})$, respectively. To include the effects of changes in labor intensity on energy sector outputs, we add a generic labor sector, which consumes the three physical products to supply hours of input labor (either physical or intellectual) to our modeled sectors (h). In each case, the intensity of inputs per unit of output in a sector is rounded to the nearest $\mathrm{OM}$ (power of 10).

One important common assumption across all sectors is the counting of labor hours. There are at least three ways of computing the number of hours required by each employee. Most narrowly, one might assume that each worker puts in $\approx 2000 \mathrm{~h}$ of labor per year. However, each worker needs to live all $8760 \mathrm{~h}$ of a year to perform $\approx 2000$ yearly hours of labor. Looking more broadly, a worker may provide $\approx$ 40 years of labor per 80 year lifetime (approximately ages 25-65) and thus lives two total life years for each year in the workforce. Thus, the ratio of total hours to productive hours is $8760 * 2 / 2000=8.76 \mathrm{~h}$ of life per hour of work.

We can also use macro-scale labor statistics from the United States to come to a similar figure. Working hours in 2014 were derived from BLS statistics (BLS 2015): 69.1\% of the over-15 population was working on a given day, an average of $38.6 \mathrm{~h}$ per week (BLS 2015). The 16 years and older population in 2015 was $251.0 \times 10^{6}$ people (BLS 2015). Therefore, worker hours were $3.48 \times 10^{11}$, while total lived hours for the 320 million US population in 2015 were $2.80 \times 10^{12}$. Thus, $\approx 8.04$ living hours are supported for each working hour. We use the broadest measure here, as one cannot have workers without also supporting youth and the elderly. We, therefore, assume $8 \mathrm{~h}$ of life required to be supported per productive worker hour.

Note that people serve two functions in this model: they are both consumers of final output and the suppliers of labor. We treat this complexity as follows: the basic subsistence requirements to provide labor to the economic process are meant to be included as part of the inter-industry A matrix, while any additional consumption to satisfy discretionary demands is treated as part of final demand. This distinction is largely theoretical in this work, but could be 
further explored in future studies with more granular datasets and matrices.

Another key methodological concern is the treatment of stocks and flows. In some cases, consumption to fuel a productive sector may occur up front (as in drilling of an oil well) while other consumption may resemble a "flow" that is required for each unit of additional production. We have (in this work) treated all consumption as a yearly flow, with any up-front capital investment averaged over the life of the project and, therefore, "smoothed" into a flow. Therefore, all steel assumed required by the oil industry is apportioned proportionally for each barrel as a "flow". Future versions of the model could work with dynamic data to incorporate investment of upfront capital and labor.

Another important consideration the possible overlap between food and energy sectors. For one, the purpose of the food sector is simply to provide energy (sustenance) to the labor sector. Second, the energy sector consumes some food sector outputs (e.g., corn for ethanol production) in some regions in some times. In a sense, the energy sector serves to provide animating power (exergy) to the built environment and machinery, while the food sector fuels the labor sector. These complexities aside, we still consider it useful to distinguish between the food and energy sectors because they are so different and fundamentally important to the economy. This is particularly the case if one is looking at long-term trends in the shift between traditional and fossil-based energy systems.

Note that in all cases, self-consumption within a sector is modeled using the on-diagonal elements. For some cases where only net output at the end of any self consumption is available (e.g., for food) we leave the diagonal element blank.

Lastly, we do not consider human physical energy expenditure important for any sector, which implies a modern economy where much or all material processing, manufacturing, construction, and transport is machine powered.

\section{Energy Sector Requirements}

The energy sector consumes energy, materials, food and labor to produce energy outputs. For the energy sector, the requirements are defined as follows:

Energy consumption by the energy sector Direct energy consumption by the energy sector, per unit of energy output, is modeled using oil industry figures as indicative. From prior work (Brandt et al. 2015, 2012; Cleveland 2005; Guilford et al. 2011) the direct self-consumption of energy within the energy sector for producing crude oil from the Earth ranges from $\leq 1$ to $30 \%$ of the energy content of produced crude oil. The high end of this range is observed in thermal enhanced oil recovery and oil sands projects. The low end of the range would be observed during primary production of a high quality (i.e., Persian Gulf) oil field. In addition, refining of crude oil into finished fuel products requires $\approx 5$ to $15 \%$ of the energy content of the crude oil, with higher values observed in processing heavy crudes. As an order-of-magnitude figure, we approximate the total energy self-consumption of both production and refining as $0.1 \mathrm{MJ} / \mathrm{MJ}$.

Material consumption by the energy sector Material consumption per oil well was found by Brandt (2015) and Beath et al. $(2012,2014)$ to be of order 100s to 1000 s tonnes of material per well. For example, Brandt's default well has direct material consumption for wellbore, cement, surface facilities, and long-distance transport of 750 tonnes per well (Brandt 2015). In the US, average per-well lifetime productivity (estimated ultimate recovery per well) is of order $130,000 \mathrm{bbl}$, while global productivities are closer to $1 \times 10^{6} \mathrm{bbl}$ per well. At a typical energy content of crude of $6100 \mathrm{MJ} / \mathrm{bbl}$, these results equal $8 \times 10^{8}$ to $6 \times 10^{9} \mathrm{MJ}$ per well. Thus, if we assume material consumption of 1000 tonnes per well $\left(1 \times 10^{6} \mathrm{~kg}\right)$ and conservative energy output of $1 \times 10^{9} \mathrm{MJ}$ per well, consumption intensity is of order $10^{-3} \mathrm{~kg}$ of material per MJ of energy.

Food consumption by the energy sector Since food is consumed to provide labor services, direct food consumption per unit of energy produced is $0 \mathrm{~kg} / \mathrm{MJ}$.

Labor consumption by the energy sector ExxonMobil is used as oil industry reference. In 2014, ExxonMobil had $73.5 \times 10^{3}$ regular employees, and produced $4.097 \times 10^{6} \mathrm{bbl}$ of oil equivalent per day (ExxonMobil 2015). Using the above $6100 \mathrm{MJ}$ ber BOE, this amounts to $9.12 \times 10^{12} \mathrm{MJ}$ per year. Of course, ExxonMobil operations will employ also non-ExxonMobil contractors or service company employees. Taking a high multiplier of 10 total employees per ExxonMobil regular employee, the per-worker productivity is $1 \times 10^{-4} \mathrm{hr} / \mathrm{MJ}$, only counting the worked hours. Correcting for the factor of $8 \mathrm{~h}$ lived per hour worked, we arrive at $1 \times 10^{-3}$ lived hours per MJ.

\section{Material Sector Requirements}

For inputs to material production processes, we use steel as the example material commodity.

Energy consumption by the materials sector IEA data (IEA 2009) suggest that energy requirements for basic oxygen furnace are of order $12-14 \mathrm{MJ} / \mathrm{kg}$, so we use a figure of $10 \mathrm{MJ} / \mathrm{kg}$.

Material consumption by the materials sector No ready data are available on direct material consumption by the materials industry. A variety of works focus on the energy intensity of material production (Gutowski et al. 1986), and some which discuss loss and recycling during supply chains (Allwood et al. 1986), but little information is available on the material consumed for building material production 
systems. For simplicity we assume that $0.1 \mathrm{~kg}$ of material is required to produce $1 \mathrm{~kg}$ of material output.

Food consumption by the materials sector Since food is consumed to provide labor services, direct food consumption per unit of material produced is $0 \mathrm{~kg} / \mathrm{MJ}$.

Labor consumption by the materials sector Nippon Steel is used as an example. Nippon Steel has $\approx 84,000$ employees, and raw steel output is $4.22 \times 10^{10}$ tonnes, so about $4 \times 10^{-6} \mathrm{~h}$ worked per kg of steel (NSSM 2016). Accounting for hours lived per hour worked, we round this to $1 \times 10^{-4} \mathrm{hrs}$ lived per $\mathrm{kg}$.

\section{Food Sector Requirements}

Energy consumption by the food sector Estimates of energy consumption by the US food sector vary widely. For example, a low-end estimate is given by US EIA Manufacturing Energy Consumption Survey for NAICS code 311 ("Food") was $1.2 \mathrm{EJ} / \mathrm{y}$ in 2010. Assuming $1000 \mathrm{~kg}$ of food consumed per year by each of 309.3 million 2010 citizens (Pimentel et al. 2008), this amounts to $4 \mathrm{MJ} / \mathrm{kg}$. That figure is almost certainly low due to lack of transport energy and likely missing other indirect energy. In contrast, Pimentel et al. (2008) suggest that direct and indirect consumption by the US food system was $\approx 75 \mathrm{MJ} / \mathrm{kg}$ food. We choose an intermediate order-of-magnitude between these at $10 \mathrm{MJ} /$ $\mathrm{kg}$.

Material consumption by the food sector Pimentel and Patzek (2005) and Patzek (2004) suggest that material requirements for equipment used for corn harvesting are about $55 \mathrm{~kg}$ per ha, while yields are about $7300 \mathrm{~kg} / \mathrm{ha}-\mathrm{y}$. These data are unavailable for further study, so we use more recent work on machinery requirements for Illinois corn production (Stubbs 2013). These more recent figures suggest machinery requirements of $33-108 \mathrm{~kg} / \mathrm{ha}$, depending on farm size. For a machinery lifetime of 20 years, this amounts to $2-5 \mathrm{~kg} / \mathrm{ha}-\mathrm{y}$. We assume the wider general agriculture industry is about 10 times more material intensive than corn production, so estimate $0.01 \mathrm{~kg}$ material consumed per $\mathrm{kg}$ of food.

Food consumption by the food sector In a modern food production system, much food is consumed internally within the sector to produce higher value products (e.g., grain used to produce meat and dairy). Because our overall energy consumption value is for the whole sector, as is our labor requirement, we do not count internal consumption in the food sector.

Labor consumption by the food sector US Bureau of labor force statistics puts 2014 employment in food production 972,000 people [Bureau of Labor Statistics (2016) codes 35-0000], while over $12 \mathrm{M}$ people work in food serving and preparation. To avoid endogenizing the discretionary consumption of labor for prepared food in restaurants, we round up the more narrowly defined food production labor pool to 1 $\mathrm{M}$. If these people all work full time ( $2000 \mathrm{~h}$ per year) to produce and serve the $1000 \mathrm{~kg}$ of food per person noted below, this amounts to 0.09 direct worked hours per $\mathrm{kg}$ of food. Accounting for hours worked per hour lived, we round this to $1 \mathrm{~h} / \mathrm{kg}$.

\section{Labor Sector Requirements}

Energy consumption by the labor sector The labor sector consumes energy directly in households. US consumption in households was $10 \mathrm{EJ}$, or $1 \times 10^{13} \mathrm{MJ}$. If we assume that $\approx$ $1 / 3$ of energy consumption was for non-discretionary uses, then basic household energy consumption per lived hour was $1 \mathrm{MJ} / \mathrm{hr}$.

Material consumption by the labor sector House construction for two studied houses consumed $\approx 80-90$ tonnes of material (Winistorfer et al. 2005). We, therefore, assume that a housing unit consumes 100 tonnes of material. Total housing starts were $\approx 1$ million per year (NAHB 2016), leading to consumption of $1 \times 10^{11} \mathrm{~kg}$, leading to consumption of $0.04 \mathrm{~kg}$ per lived hour. Adding in additional non-housing material, we arrive at $0.1 \mathrm{~kg}$ per lived hour.

Food consumption by the labor sector FAO [FAO (2003) Table 2.7] gives 2015 food consumption for industrial countries at $1064 \mathrm{~kg}$ per person per year, including indirectly consumed grain (e.g. grain consumed by animals). This amounts to $0.12 \mathrm{~kg}$ of food per lived hour, which we round to $0.1 \mathrm{~kg} / \mathrm{h}$ lived.

Labor consumption by the labor sector Because the BLS statistics shown above include all labor sources, we do not include any factor of additional labor self-consumption to provide labor.

In comparison to some IO models where household demand is entirely exogenous and part of final demand, in this model we have partly endogenized household demand. Conceptually, we endogenize into the labor sector all household consumption required (at a basic level) to support the supply of labor, while the remaining discretionary household consumption is exogenous. This distinction, while only approximate and "fuzzy", at least conceptually allows us to include labor provision within the system while recognizing that much of final demand is in fact consumed by laborers (though for discretionary uses).

After these calculations, the resulting "baseline" matrix for our simple order-of-magnitude four sector economy is given below in Eq. 13:

$\begin{array}{ccccc} & \text { En. } & \text { Mat. } & \text { Fd. } & \text { Lab. } \\ \text { Energy } & 0.1 & 10 & 10 & 1 \\ \text { Materials } & 10^{-3} & 0.1 & 0.01 & 0.1 \\ \text { Food } & 0 & 0 & 0 & 0.1 \\ \text { Labor } & 10^{-3} & 10^{-4} & 0.1 & 0\end{array}$




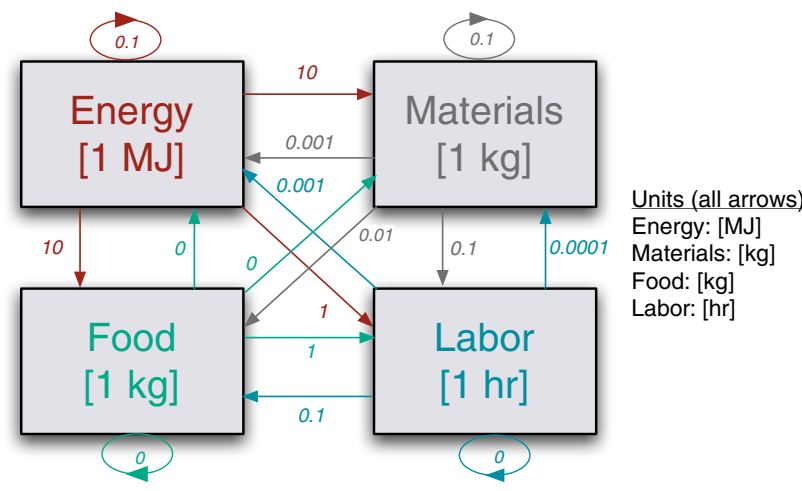

Fig. 2 Illustration of cross-sector flows in "baseline" example model

We also illustrate these flows in Fig. 2.

\section{Exploring Impacts of Reduced Energy Sector Productivity on Our Model Economy}

Now that our template four-sector model is complete, we explore ways to model reduced productivity of the energy sector. In reality, depletion of energy resources is a complex phenomenon, resulting in myriad physical impacts. We will model these complex impacts simply by perturbing the column of the A matrix that represents the inputs to the energy sector.

We do this by scaling the energy column of the matrix by a multiplier. In the Figures below, we explore the range of columnar multipliers from $0.5 \times$ to $10 \times$. This range is explored in 100 steps. For each value of the multiplier, the resulting GER is computed for each range of energy inputs as above.

\section{Results}

We first plot the resulting fraction free for each product of the economy as a function of the resulting NER and GER in Fig. 3. The average fraction free drops moderately below NER $=4$ (see solid black line in Fig. 3a) and begins precipitous decline below NER $=2$. Note that at a certain level of requirement for the energy sector, the solution to the system of equations becomes non-physical (i.e., below NER $=1$ ). In mathematical terms, the requirements to produce even a single unit of positive final demand approach $\infty$ as the system approaches a critical point. Beyond this critical level of intensity, the solutions to the system of equations become negative, a non-physical and non-sensical solution. This occurs when the economy fails to satisfy the classic Hawkins-Simon condition for the viability of an economic system (Miller and Blair 2009). By definition of NER and

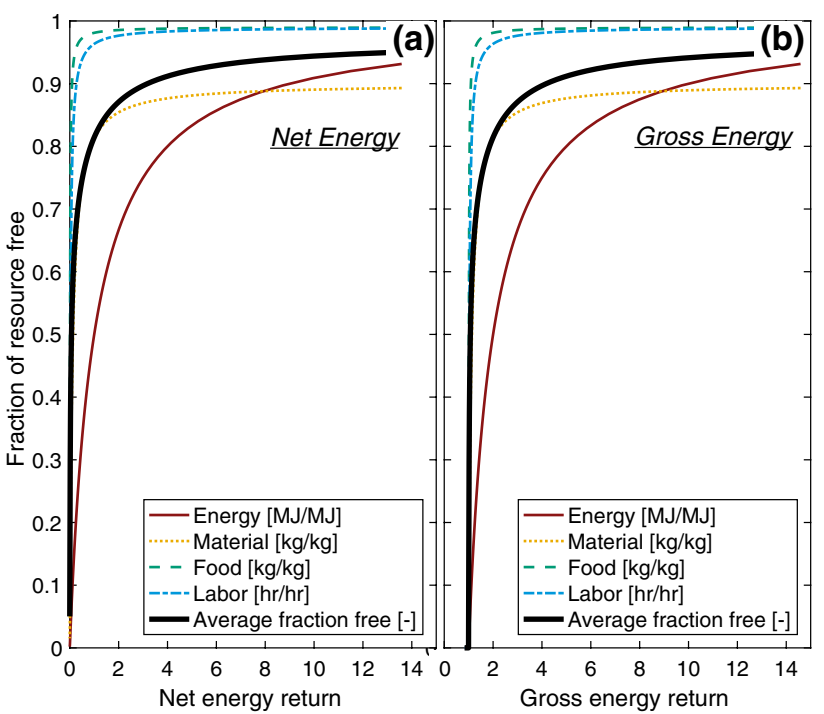

Fig. 3 Changes of free fraction of each resource $r_{i}$ created by starting with the above "baseline" example model and steadily increasing the intensity of the energy sector requirements column. a The fraction free as a function of net energy return (NER), while b shows the fraction free as a function of gross energy return (GER)

GER, the GER results shown in Fig. $3 b$ are equivalent but shifted by 1 unit since GER $\leq 1$ becomes non-physical.

Because each of the above terms in the baseline orderof-magnitude matrix is uncertain, we explore in detail the effects of uncertainty on the results of our computations. An uncertainty multiplier matrix is thus defined as $\mathbf{U}$ and each realization of the uncertainty-informed matrix $\mathbf{A}$ is computed as:

$\mathbf{A}_{u}=\mathbf{A} \circ \mathbf{U}$

where $\circ$ represents the Hadamard product of element-wise multiplication (not the same operation as conventional matrix multiplication). The $\mathbf{U}$ matrix is constructed with each term an independent number drawn from a lognormal distribution with $\mu=0.5$ and $\sigma=1$. Thus, $\approx 95 \%$ of the time, each element of $\mathbf{U}$ is between 0.25 and 12 .

Once each realization of $\mathbf{A}_{u}$ is created, the increasing intensity of the energy sector is again applied to the matrix, and the impacts on the fraction free of each resource is tracked as the energy sector productivity degrades as measured by GER. The result of these computations for 1000 realizations is shown in Fig. 4. Note that there is no uncertainty between the fraction of energy resource free and the GER, as there is a one-to-one relationship between NER and $r_{\mathrm{en}}$.

We see that despite the uncertainty in the terms of $\mathbf{A}$, the overall behavior of decreasing fraction free $r_{i}$ as a function of GER is consistent, though the level of resource free at high GERs differs somewhat, as does the level of GER at which degradation in $r_{i}$ begins. 
Fig. 4 Range of fraction product free for each product under 1000 realizations of uncertainty analysis for declining resource productivity. All are plotted as function of gross energy return (GER). Results from baseline model as plotted above are shown in bold

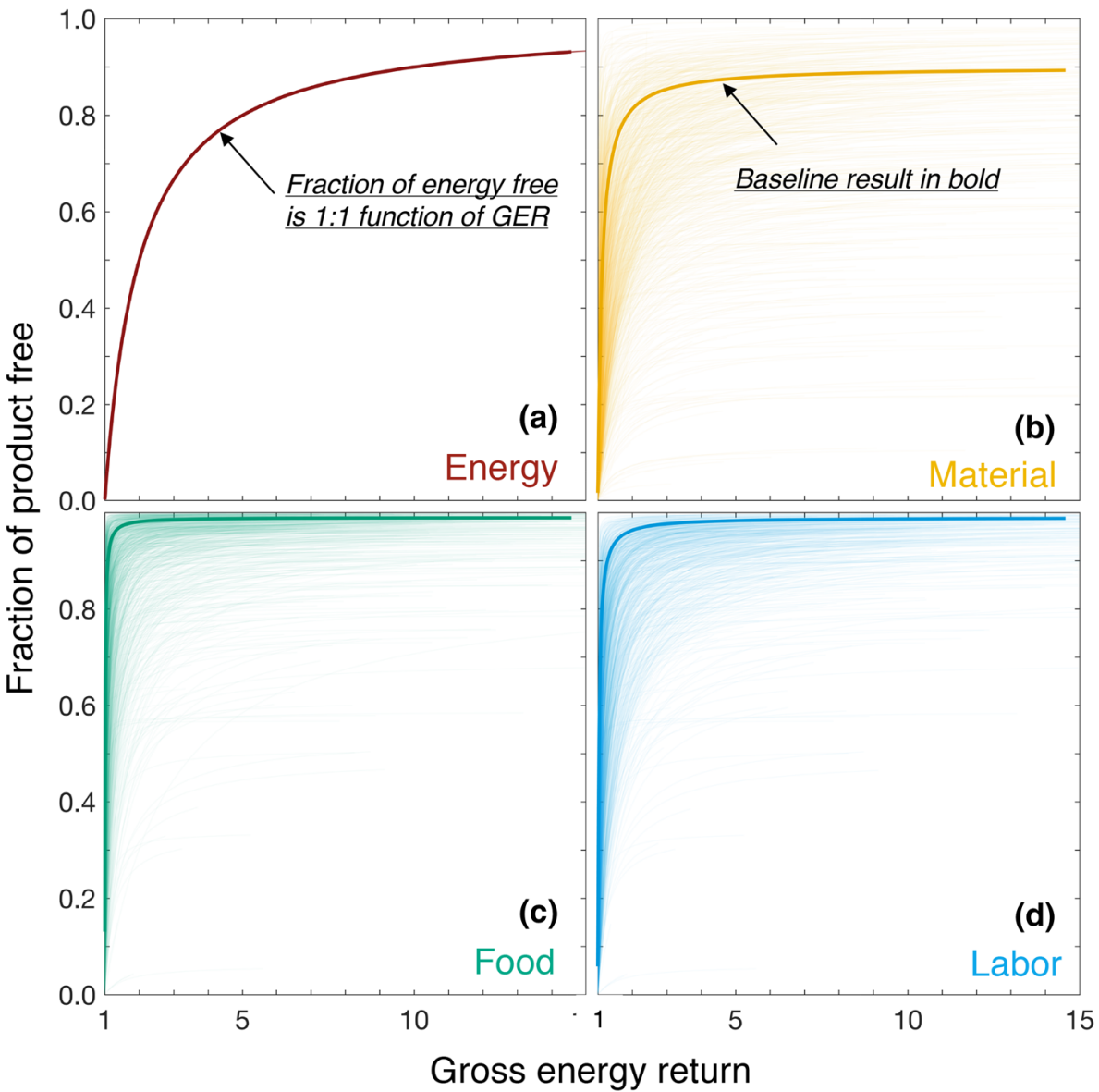

Importantly, energy resource productivity as measured by the intensity of the energy sector requirements matrix is not the only factor that affects the fraction of a particular resource that is free (or of the average fraction free of a basket) of goods. For example, in Fig. 5 we double the intensity vector for each non-energy column and then apply sensitivity analysis as above, computing the average (arithmetic mean) fraction free across our four primary products. Each grey line in Fig. 5 represents one realization of the black line in Fig. 3. We cross a threshold value of $\theta=0.66$ between for sensitivity-defined NER cutoffs of between 1.1 and $15 \mathrm{MJ} / \mathrm{MJ}$. We see that food sector inputs are the most sensitive driving variable.

Note that in a scenario where, say, the materials sector productivity declines, there could be substitution in the energy sector to replace materials with labor and other inputs. More generally, if one product becomes more scarce, expensive, or (indirectly) energy intensive, then the energy sector could substitute some of this product with other products. This would mitigate some of the effects seen in these cases. Further exploration of systems with substitutability is beyond the scope of this paper.

\section{Conclusions}

We see that the productivity of the energy sector, parameterized and measured using the indicators of NER or GER, is directly related to the prosperity of the production process, measured as the fraction of a given sector's output that can be allocated to discretionary outputs. As the energy sector becomes less productive, it consumes more materials, labor and energy, and the output of the other sectors of society is increasingly dedicated to supplying inter-industry demand of the energy sector. As we noted above with decomposing the changes in $\mathbf{s}$, this effect occurs both directly through increased use of energy by the energy sector itself as well as indirectly through higher order terms of the summation form of the $\mathbf{A}^{-1}$ matrix computation. Thus, the mechanism by which energy sector productivity affects overall prosperity is twofold: direct increases in material and energy use by the energy sector (i.e., changes due to changes in the energy column of $\mathbf{A}$ ), and indirect increases due increased consumption of output of other sectors (i.e., changes not in $\mathbf{A}$ but in $\mathbf{L}$ ). 


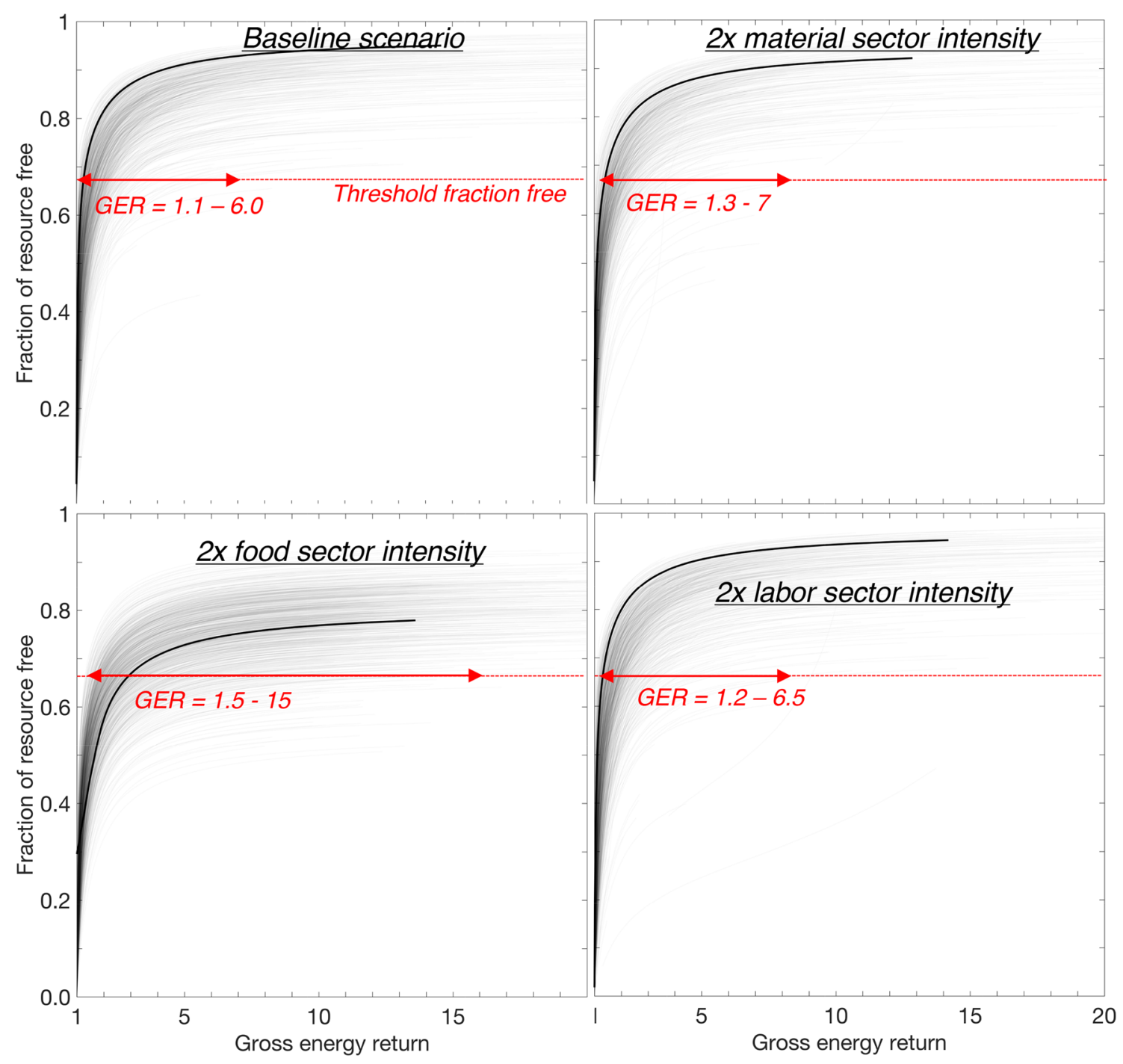

Fig. 5 Range of average fraction resource free change due to doubling intensity of other sectors

Notably, the so-called "net energy cliff" (Murphy 2014) is observed in all results from this model. This is interesting because the method by which EORI and net energy availability are computed in this model is different from those used in prior studies, yet similar qualitative behavior is observed. The reduction in the fraction of a resource free and the energy system productivity extends from the energy system to all aspects of the economy, which gives an indication of the mechanisms by which energy productivity declines would affect general prosperity.

Future work in this area should study the dynamics of energy sector development and technological change. For example, one could use such coupled multi-sector models to study the transition from biomass to fossil energy, which was the result of multiple complex systems evolving together with positive feedback observed between materials and energy sectors (for example, see Sorrell's argument about the coal-steel-steam complex of early English industrial development) (Sorrell 2010).

Clearly, the substitution of abundant resources for resources of increasing scarcity should be addressed in future models. The fixed coefficients model used in exploring sensitivity to changes in a particular column of the matrix (as in Fig. 5) does not allow that the other columns (sectors) may respond by substituting away from the newly scarce resource. A future model should account for such possibilities by allowing a substitution effect to occur as in models with multi-factor production functions. Such functions would need to be sector specific and ideally supported with significant data collection, so are left for future work.

Another interesting area of (more broad) future extensions could look at impacts of resources that could be degraded or improved and/or remediated. For example, the current model examines the effect of declining energy 
productivity as the resource base is degraded and exploited. However, some systems, including bio-energy or food production systems can both be degraded and remediated. It would be an interesting extension to explore the effects of increasing investments into a given sector to remediate damage or maltreatment, which could have increasing dividends in a dynamic model.

Future work could also focus on the implications of shifts in material flows and net energy availability associated with gradual transitions from fossil to renewable energy sources. These models could be particularly interesting if they leveraged the highly detailed process-based life cycle databases such as the EcoInvent database (Ecoinvent Centre 2014). Of perhaps more interest, a dynamic model could account for the differences in systems where energy returns decline gradually or decline sharply. Such dynamic models have been attempted in the past for less general cases (e.g., looking at oil price shocks) (Heun and de Wit 2012).

A clear implication of this work is that decreases in energy resource productivity, modeled here as the requirement for more materials, labor, and energy, can have a significant effect on the flows required to support all sectors of the economy. Such declines can reduce the effective discretionary output from the economy by consuming a larger and larger fraction of gross output for the meeting of interindustry requirements. These impacts would emerge by reducing the "fraction free" of available output from various sectors. We see different threshold "minimum EROI" values for different assumptions about the fraction of outputs that can be absorbed to inter-industry demand without affecting prosperity. At reasonable vales of the critical fraction free, we see minimum EROI values that align with results from the prior literature.

\section{References}

Allwood JM, Ashby MF, Gutowski T, Worrell E (2013) Material efficiency: providing material services with less material production. Philos Trans R Soc A 371:1986

Beath J, Black N, Boone M, Roberts GBR, Elgowainy A Wang MJK (2014) Contribution of infrastructure to oil and gas production and processing carbon footprint. Tech. rep., Argonne National Laboratory

Beath J, Boone M, Wang MQ, Elgowainy A (2012) Contribution of infrastructure to oil and gas production and processing carbon footprint. Tech. rep, Argonne National Laboratory and ERM

BLS (2015) Labor force statistics from the current population survey. Tech. rep., Bureau of Labor Statistics

Brandt A (2015) Embodied energy and GHG emissions from material use in conventional and unconventional oil and gas operations. Environ Sci Technol. doi:10.1021/acs.est.5b03540

Brandt AR, Dale M (2011) A general mathematical framework for calculating systems-scale efficiency of energy extraction and conversion: energy return on investment (EROI) and other energy return ratios. Energies 4(8): 1211-1245. doi:10.3390/ en4081211. http://www.mdpi.com/1996-1073/4/8/1211/

Brandt AR (2011) Oil depletion and the energy efficiency of oil production: the case of California. Sustainabilities 3(10):18331844. doi:10.3390/su3101833

Brandt AR, Englander J, Bharadwaj S (2012) The energy efficiency of oil sands extraction: energy return ratios from 1970 to 2010 . Energy 55:693-702

Brandt AR, Dale M, Barnhart CJ (2013) Calculating systems-scale energy efficiency and net energy returns: a bottom-up matrixbased approach. Energy 62:235-247

Brandt A, Sun Y, Bharadwaj S, Livingston D, Tan E, Gordon D (2015) Energy return on investment (EROI) for forty global oilfields using a detailed engineering-based model of oil production. PLoS One 10(12):e0144,141

Bureau of Labor Statistics (2016) Industry-occupation matrix data, by occupation. US Bureau of Labor Statistics. Accessed December

Cleveland CJ, Kaufman RK, Stern DI (2000) Aggregation and the role of energy in the economy. Ecol Econ 32(2):301-317

Cleveland CJ (2005) Net energy from the extraction of oil and gas in the united states. Energy 30:769-782

Deffeyes KS (2005) Beyond oil: the view from Hubbert's peak. Hill and Wang, New York

Ecoinvent Centre. Ecoinvent v.3.0 dataset. Swiss Centre for Life Cycle Inventories (2014)

ExxonMobil (2015) Financial and operating review: 2015. Tech. rep., ExxonMobil

FAO (2003) World agriculture: towards 2015/2030. Tech. rep., Food and Agriculture Organization

Fouquet R (2008) Heat, Power and light: revolutions in energy services. Edward Elgar Publishing, Northampton

Guilford MC, Hall CA, O'Connor P, Cleveland CJ (2011) A new long term assessment of energy return on investment (EROI) for US oil and gas discovery and production. Sustainability 3(10):1866-1887. doi:10.3390/su3101866.http://www.mdpi. com/2071-1050/3/10/1866

Gullickson W, Harper MJ (1987) Multifactor productivity in US manufacturing, 1949-83. Mon Labor Rev

Gutowski T, Sahni S, Allwood JM, Ashby MF, Worrell E (2013) The energy required to produce materials: constraints on energyintensity improvements, parameters of demand. Philos Trans R Soc A 371:1986

Hall CAS, Cleveland CJ, Kaufmann R (1986) Energy and resource quality: the ecology of the economic process. Wiley, New York

Hall CAS, Tharakan P, Hallock J, Cleveland C, Jefferson M (2003) Hydrocarbons and the evolution of human culture. Nature 426(6964):318-322

Hall CAS, Balogh S, Murphy J (2009) What is the minimum EROI that a sustainable society must have? Energies 2:25-47

Hall CAS, Cleveland CJ (1981) Petroleum drilling and production in the united states-yield per effort and net energy analysis. Science 211(4482):576-579

Heijungs R, Suh S (2002) The computational structure of life cycle assessment. Springer, New York

Heun M, de Wit M (2012) Energy return on (energy) invested (EROI), oil prices, and energy transitions. Energy Policy 40:147-158

IEA (2009) Transport, energy and $\mathrm{CO}_{2}$ : Moving toward sustainability. Tech. rep., International Energy Agency

King CW, Maxwell John P, Donovan A (2015) Comparing world economic and net energy metrics, Part 1: Single technology and commodity perspective. Energies 8(11):12949-12974

King CW, Hall CAS (2011) Relating financial and energy return on investment. Energies 3:1810-1832

Lambert J, Hall CAS, Balogh S, Gupta A, Arnold M (2014) Energy, EROI and quality of life. Energy Policy 64:153-167 
Miller RE, Blair PD (2009) Input-output analysis: foundations and extensions, 2nd edn. Cambridge University Press, Cambridge

Murphy DJ, Hall CAS, Dale M, Cleveland CJ (2011) Order from chaos: a preliminary protocol for determining EROI of fuels. Sustainabilities 3:1888-1907

Murphy DJ (2014) The implications of declining energy return on investment of oil production. Philos Trans R Soc A 372:20130126

Murphy DJ, Hall CAS (2010) Year in review: EROI or energy return on (energy) invested. Ann N Y Acad Sci (Ecological Economics Reviews) 1185:102-118. doi:10.1111/j.1749-6632.2009.05282.x

NAHB (2016) Housing starts and permits. Corporate report: May 2016, National Association of Homebuilders

NSSM (2016) Annual report 2016. Corporate report: Nippon Steel \& Sumitomo Metal

Patzek T (2004) Thermodynamics of the corn-ethanol biofuel cycle. Crit Rev Plant Sci 23(6):519-567

Perlin J (1989) A Forest Journey: the role of wood in the development of civilization. Norton, W.W

Pimentel D, Williamson S, Alexander CE, Gonzales-Paga O, Kontak C, Mulkey SE (2008) Reducing energy inputs in the US food system. Hum Ecol 36:459-471
Pimentel D, Patzek TW (2005) Ethanol production using corn, switchgrass, and wood; Biodiesel production using soybean and sunflower. Nat Resour Res 14(1):65-76. doi:10.1007/ s11053-005-4679-8

Smil V (1994) Energy in world history. Essays in World History. Westview Press, Boulder

Sorrell S (2010) Energy, economic growth and environmental sustainability: five propositions. Sustainability 2(6):1784-1809

Stubbs BJ (2013) Energy usage of agricultural machinery for corn and soybean production in Brazil, India, USA, and Zambia. Ph.D. thesis, University of Illinois at Urbana-Champaign

Tainter JA (1988) The collapse of complex societies. Cambridge University Press, Cambridge

Winistorfer P, Chen Z, Lippke B, Stevens N (2005) Energy consumption and greenhouse gas emissions related to the use, maintenance and disposal of a residential structure. Wood Fiber Sci $37: 128-139$ 